\title{
Synthesis, Characterization and Application of O, O-diethyl Acrylamide Phosphate
}

\author{
Aibing Jiang \\ Tianjin Municipal Key Laboratory of Fiber Modification and Functional Fiber \\ Tianjin Polytechnic University, Tianjin 300160, China \\ School of Textile, Tianjin Polytechnic University, Tianjin 300160, China \\ E-mail: jiangaibing58@sina.com \\ Bowen Cheng, Yuanlin Ren \& Zhenhuan Li \\ Tianjin Municipal Key Laboratory of Fiber Modification and Functional Fiber \\ Tianjin Polytechnic University, Tianjin 300160, China
}

\begin{abstract}
Taking acrylamide and diethyl chlorophosphate as the reactants, we synthesized a sort of new intumescent flame retardant (IFR) containing phosphorus and nitrogen, O,O-diethyl acrylamide phosphonate. The structure of the title compound could be characterized by FTIR, ${ }^{1} \mathrm{H}$ NMR and MS. The results show that the structure of the synthesized compound is consistent with the expected structure. The yield of the title compound is $75 \%$ under the conditions that the molar ratio between acid-binding agents of triethylamine and acrylamide is $1: 1$ and the mass fraction of the catalys $\mathrm{CuCl}$ is $1 \%$ of acrylamide. The optimal reaction temperature range is from $20^{\circ} \mathrm{C}$ to $30^{\circ} \mathrm{C}$. The limiting oxygen index (LOI) value can reach $26.7 \%$ when the mass fraction of the title compound in the copolymer is $20 \%$. The scanning electron microscopy (SEM) photos of the fired residue of the flame retarded copolymer show that the surface of the fired residue presents foam-like structure, and the cross section presents cellular structure, which indicate that the title compound is the intumescent flame retardant.
\end{abstract}

Keywords: O, O-diethyl acrylamide phosphate, Intumescent flame retardant, LOI, SEM

\section{Introduction}

In recent years, the intumescent flame retardant is one of $R \& D$ hotspots in the domain of flame retardant. It is the composite flame retardant taking nitrogen, phosphorus and carbon as bases and it doesn't contain halogen and adopt antimony pentoxide as synergy agents, but it possesses the synergy function itself (Chigwada, 2003, P.551-557, Duquesne, 2002, P.333-344, Zhang, 2002, P.5463-5472, Horacek, 1996, P.205-215, Wyman, 2006, P.764-771, He, 2008, P.104-108). When this sort of flame retardant is used in the fame retardant materials which are heated, the surface of the materials will form loose carbon layer with closed structure which can retard burning, isolate oxygen and eliminate smoke, so this type flame retardant possesses excellent fame retardant performances (Schartel, 2006, P.8495-8508, Lewin, 2002, P.1091-1102, Yan, 2007, P.6-7, Ju, 2008, P.5-7, Ren, 2007, P.1314-1317, Zhang, 2007, P.831-834). So we synthesize a sort of new intumescent flame retardant containing phosphorus and nitrogen, and copolymerize it with acrylonitrile to form the flame retardant acrylonitrile copolymer. We measure the LOI value of the flame retardant copolymer by the LOI meter and analyze the flame retardant mechanism of the title compound through the SEM test of the carbon residue of burned flame retardant copolymer.

\section{Experiment}

\subsection{Reagents and Apparatus}

Reagents used in the experiment include acrylamide (analytical reagent, being ready for recrystallizing), acetone (analytical reagent, being ready for distillation), anhydrous (analytical reagent, being ready for distillation), acrylonitrile (analytical reagent, being ready for distillation), phosphorus oxychloride (analytical reagent, it can be used directly), triethylamine (analytical reagent, it can be used directly), and cuprous chloride (analytical reagent, it can be used directly). 
Apparatuses used in the experiment include Bruker Vector 22 (Germany) Fourier Infrared Spectrum Meter, KBr pressed disk, Bruker AC-P2000 NMR Equipment (US), solvent $\mathrm{CDCl}_{3}$, internal standard TMS, VG-ZAB-HS mass spectrograph (Germany), Quanta 200 environmental SEM (Zcech), and Stanton Redcroft FTA oxygen analyzer (Britain).

\subsection{Synthesis of diethyl phosphorus oxychloride}

Put $91.54 \mathrm{ml}$ phosphorus oxychloride into the flask with four standard necks of $500 \mathrm{ml}$, and put $116.45 \mathrm{ml}$ anhydrous ethanol into the press-constant dropping funnel, and slowly drop the anhydrous ethanol into the flask in 2 hours, and control the reaction temperature in $0^{\circ} \mathrm{C} \sim 5^{\circ} \mathrm{C}$ and stop the reaction after 4 hours, and react in the room temperature for 10 hours. Decompress and distill the reaction production $\left(73^{\circ} \mathrm{C}, 1.15 \mathrm{kPa}\right)$, and the liquid obtained is O,O-diethyl acrylamide phosphonate (Sundarrajan, 2001, P.41-45 \& Devi, 2002, P.2461-2467), and the relative density $\rho$ is 1.192 $\mathrm{g} / \mathrm{cm}^{3}$.

\subsection{Synthesis of $O$, O-diethyl acrylamide phosphate}

Put $120 \mathrm{ml}$ acetone, $34.72 \mathrm{~g}$ acrylamide, $69 \mathrm{ml}$ triethylamine and $0.35 \mathrm{~g} \mathrm{CuCl}$ into the flask with four standard necks of $250 \mathrm{ml}$, and mix round by the magnetic force beater evenly, and put $70.71 \mathrm{ml}$ diethyl phosphorus oxychloride into the press-constant dropping funnel, and slowly drop the anhydrous ethanol into the flask in 1 hour, and control the reaction temperature in $20^{\circ} \mathrm{C} \sim 30^{\circ} \mathrm{C}$ and stop the reaction after 6 hours, and react in the $60^{\circ} \mathrm{C}$ for 18 hours. Filtrate, decompress and distill the reaction production, and the oily liquid obtained is the title compound, and the relative density $\rho$ is 1.113 $\mathrm{g} / \mathrm{cm}^{3}$.

\subsection{Synthesis of flame retardant polyacrylonitrile copolymer}

Add nitrogen gas into the flask with four standard necks of $500 \mathrm{ml}$ to eliminate the oxygen in the flask, and put $10.35 \mathrm{~g}$ O,O-diethyl acrylamide phosphonate into the flask, and put $51 \mathrm{ml}$ acrylonitrile into the flask with four standard necks, and add $141 \mathrm{ml}$ DMSO acting as the solvent, and mix round evenly, and when the temperature increases to $40^{\circ} \mathrm{C}$, add $0.36 \mathrm{~g}$ azobisisbutyronitrile (AIBN) and control the temperature in $65^{\circ} \mathrm{C}$ to react for 8 hours and produce white viscous fluids, and wash the fluids by anhydrous ethanol, and wash the fluids by distilled water three times, and desiccate the fluids, we can obtain the flame retardant polyacrylonitrile copolymer. The synthesis routes include following shemes.

\section{Result and discussions}

\subsection{Production structure analysis}

The infrared spectrum of the title compound is seen in Figure 1. In the figure, the position of 3384 is the flex oscillation absorption peak of $\mathrm{N}-\mathrm{H}$ bond, and the position of 1711 is the flex oscillation absorption peak of $\mathrm{C}=\mathrm{O}$ bond, and the position of 1667 is the flex oscillation absorption peak of $\mathrm{C}=\mathrm{C}$ bond, and the position of 1476 is the symmetric bending oscillation absorption peak of $-\mathrm{CH}_{2}$ - bond, and the position of 1397 is the flex oscillation absorption peak of C-O bond, and the position of 1232 is the oscillation absorption peak of $\mathrm{P}=\mathrm{O}$ bond, and the position of 1036 is the flex oscillation absorption peak of P-O-C bond, and the position of 2988 is the asymmetric flex oscillation peak of $-\mathrm{CH}_{3}$ - bond.

The ${ }^{1} \mathrm{H}$ NMR spectrum and MS spectrum of the title compound are respectively seen in Figure 2 and Figure 3 . There are five groups of peak in the ${ }^{1} \mathrm{H}$ NMR spectrum, and the multiple peak between $\delta=3.9915 \sim 4.0868$ is the chemical displacement of $\mathrm{H}(1)$, and the multiple peak between $\delta=5.7238 \sim 5.7571$ is the chemical displacement of $\mathrm{H}$ (2), and the multiple peak between $\delta=6.1504 \sim 6.3605$ is the chemical displacement of $\mathrm{H}$ (3), and the multiple peak between $\delta=3.1171 \sim 3.1399$ is the chemical displacement of $\mathrm{H}$ (4), and the multiple peak between $\delta=1.2884 \sim 1.3778$ is the chemical displacement of $\mathrm{H}$ (5).

From Figure 3, the molecule hydronium peak of the title compound is 207, which accords with the molecular weight of the anticipated title compound. $\mathrm{m} / \mathrm{z}=191$ is the corresponding fragment peak of the group of $\mathrm{C}_{7} \mathrm{H}_{14} \mathrm{O}_{3} \mathrm{NP}$, and $\mathrm{m} / \mathrm{z}=177$ is the corresponding fragment peak of the group of $\mathrm{C}_{6} \mathrm{H}_{12} \mathrm{O}_{3} \mathrm{NP}$, and $\mathrm{m} / \mathrm{z}=163$ is the corresponding fragment peak of the group of $\mathrm{C}_{5} \mathrm{H}_{10} \mathrm{O}_{3} \mathrm{NP}$, and $\mathrm{m} / \mathrm{z}=147$ is the corresponding fragment peak of the group of $\mathrm{C}_{5} \mathrm{H}_{10} \mathrm{O}_{2} \mathrm{NP}$, and $\mathrm{m} / \mathrm{z}=133$ is the corresponding fragment peak of the group of $\mathrm{C}_{5} \mathrm{H}_{10} \mathrm{O}_{2} \mathrm{P}$, and $\mathrm{m} / \mathrm{z}=119$ is the corresponding fragment peak of the group of $\mathrm{C}_{4} \mathrm{H}_{8} \mathrm{O}_{2} \mathrm{P}$, and $\mathrm{m} / \mathrm{z}=73$ is the corresponding fragment peak of the group of $\mathrm{C}_{3} \mathrm{H}_{5} \mathrm{O}_{2}$, and $\mathrm{m} / \mathrm{z}=59$ is the corresponding fragment peak of the group of $\mathrm{C}_{2} \mathrm{H}_{3} \mathrm{O}_{2}$, and $\mathrm{m} / \mathrm{z}=45$ is the corresponding fragment peak of the group of $\mathrm{C}_{2} \mathrm{H}_{5} \mathrm{O}$, and $\mathrm{m} / \mathrm{z}=31$ is the corresponding fragment peak of the group of $\mathrm{CH}_{3} \mathrm{O}$.

Through above analysis, the structure of the synthesized title compound is consistent with the anticipated structure.

\subsection{Influences of acid-binding agent and reactive temperature on the synthesis of title compound}

In the synthesis process of $\mathrm{O}, \mathrm{O}$-diethyl acrylamide phosphonate, $\mathrm{HCl}$ gas will produce, so we adopt the method adding the acid-binding agent to quicken the reaction speed and enhance the yield. The researches indicate that when the triethylamine is singly used as the acid-binding agent, the yield is low, and when a small quantity of $\mathrm{CuCl}$ is added as the activator, the yield can achieve $75 \%$, and the reaction time could be reduced. Finally, we add the triethylamine with same molar acrylamide as the acid-binding agent, and add the $\mathrm{CuCl}$ which mass fraction is $1 \%$ acrylamide as the activator. 
Because the synthesis reaction of O,O-diethyl acrylamide phosphonate is the exothermic reaction, so we must strictly control the reaction temperature in the synthesis process, or else, ascending temperature will influence the yield and possibly produce outgrowth. Therefore, we select the optimal reaction temperature in $0^{\circ} \mathrm{C} \sim 5^{\circ} \mathrm{C}$.

\subsection{LOI measurement of flame retardant polyacrylonitrile copolymer}

Copolymerize O,O-diethyl acrylamide phosphonate and acrylonitrile with different masses to obtain the flame retardant polyacrylonitrile copolymer containing diethyl acrylamide phosphonate with different mass fractions, and dissolve the copolymers into the solution of DMSO with $20 \%$ of mass fraction, and we can obtain even flame retardant polyacrylonitrile copolymer dope. Scrape the membrane and desiccate according the standard of GB2406-8, and measure the LOI. The result indicates that when the mass fraction of O,O-diethyl acrylamide phosphonate in polyacrylonitrile is $20 \%$, the LOI of the flame retardant polyacrylonitrile copolymer can achieve $26.7 \%$, which shows O,O-diethyl acrylamide phosphonate is the reactive flame retardant with better effect.

\subsection{SEM analysis of burned carbon residue of flame retardant polyacrylonitrile copolymer}

From Figure 4, the carbon residue surface of polyacrylonitrile presents foam structure, and the cross-section presents cellular structure, which accords with the flame retardant mechanism of the intumescent flame retardant. That shows the flame retardant synthesized in the article is the intumescent flame retardant, and it is consistent with the anticipated situation.

\section{Conclusions}

Taking acrylamide and diethyl phosphorus oxychloride as the reactants, we synthesized a sort of new intumescent flame retardant (IFR) containing phosphorus and nitrogen, O,O-diethyl acrylamide phosphonate. The structure of the title compound could be characterized by FTIR, ${ }^{1} \mathrm{H}$ NMR and MS. And we copolymerize the reactive flame retardant with acrylonitrile to form the flame retardant acrylonitrile copolymer which LOI value can reach $26.7 \%$ through LOI testing. The SEM photos of the fired residue of the flame retarded copolymer show that the surface of the fired residue presents foam-like structure, and the cross section presents cellular structure, which indicate that the title compound is the intumescent flame retardant.

\section{References}

Chigwada G \& Wilkie C A. (2003). Synergy between conventional phosphorus fire retardants and organically-modified clays can lead to fire retardancy of styrenics. Polym Degrad Stab, No. 81(3), P. 551-557.

Devi R R, Saikia C N, Thakur A J, Maji T K. (2002). Modification of rubber wood with styrene in combination with diethyl allyl phosphate as the flame-retardant agent. $J$ Appl Polym Sci., No. 105(5), P. 2461-2467.

Duquesne S, Delobel R, Le Bras M, et al. (2002). A comparative study of the mechanism of action of ammonium polyphosphate and expandable graphite in polyurethane. Polym Degrad Stab, No. 77(2), P. 333-344.

He, Qingdong, Cao, Youming \& Cenlan. (2008). Research Progress on Environment-friendly and High Efficient Intumescent Flame Retardants. Plastics Science and Technology, No. 36(2), P. 104-108.

Horacek H, Grabner R. (1996). Advantages of flame retardants based on nitrogen compounds. Polym Degrad Stab, No.54, P. 205-215.

Ju, Changxun, Majing \& Wang, Xinlong. (2008). Recent Advances for Research on Intumescent Flame Retardants. Plastic Additives, No. 5, P. 5-7.

Lewin M,Brozek J. \& Martens M M. (2002). The system polyamide/sulfamate/dipentaerythritol: Flame retardancy and chemical reactions. Polym Adv Tech, No.13, P. 1091-1102.

Ren, Yuanlin, Cheng, Bowen \& Zhang, Jinshu. (2007). Synthesis and Fire Retardance of N,N'-Bis(2-thio-5,5-dimethyl-1,3,2-dioxaphosphorinane) Ethane. Chinese Journal of Applied Chemistry, No. 24(11), P. 1314-1317.

Schartel B, Braun U, Balabanovich A I, Knoll U, Artner J, Ciesielski M, Doring M, Perez R, Sandler J.K.W, Altstadt V, Hoffmann T, Pospiech D. (2006). Influence of the oxidation state of phosphorus on the decomposition and fire behavior of flame-retarded epoxy resin composites. Polymer, No. 47(26), P. 8495-8508.

Sundarrajan S, Kishore K, Ganesh K. (2001). A new polymeric flame retardant additive for vinyl polymers. Indian J Chem Technol, No. 40(1), P. 41-45.

Wyman P, Crook V, Ebdon J, Hunt B, Joseph P. (2006). Flame-retarding effects of dialkyl-p-vinylbenzyl phosphonates in copolymers with acrylonitrile. Polymer Int, No.55(7), P. 764-771.

Yan, Xiaohong \& Zhang, Lifu. (2007). Preparation of New Flame Retardant Containing Nitrogen Phosphorus. Journal of Flame Retardant Material and Technology, No. 6, P. 6-7.

Zhang H, Westmoreland P R, Farris R J, et al. (2002). Thermal decomposition and flammability of fire-resistant 
UV/visible-sensitive polyarylates copolymers and blends. Polymer, No. 43(20), P. 5463-5472.

Zhang, Jinshu, Cheng, Bowen \& Ren, Yuanlin. (2007). Synthesis and Characterization of 1,4-Di(O,O-diethyl thiophosphorylimine) Benzene. Chinese Journal of Applied Chemistry, No. 24(7). P. 831-834.

$$
\mathrm{CH}_{3} \mathrm{CH}_{2} \mathrm{OH}+\mathrm{POCl}_{3} \longrightarrow \mathrm{O}^{\circ} \mathrm{C} \longrightarrow \mathrm{C}_{2} \mathrm{H}_{5} \mathrm{O}-\prod_{\mathrm{Cl}}^{\mathrm{P}}-\mathrm{OC}_{2} \mathrm{H}_{5}+2 \mathrm{HCl}
$$

Scheme 1. Synthesis route of diethyl phosphorus oxychloride<smiles>C=CC(N)=O</smiles>

Scheme 2. Synthesis route of the title compound<smiles>CCCCCCCCCCC(C)(C)CC(CC1CCC1)C(=O)NP(=O)(OCC)OCC</smiles>

Scheme 3. Synthesis route of the flame retardant polyacrylonitrile copolymer

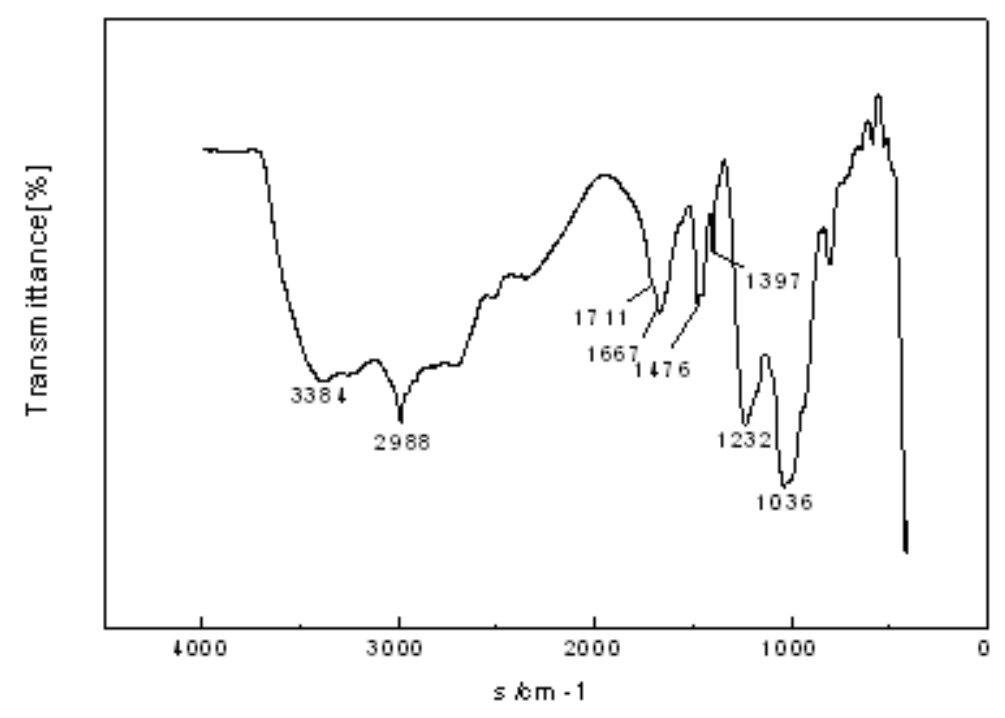

Figure 1. Infrared Spectrum of the Title Compound 


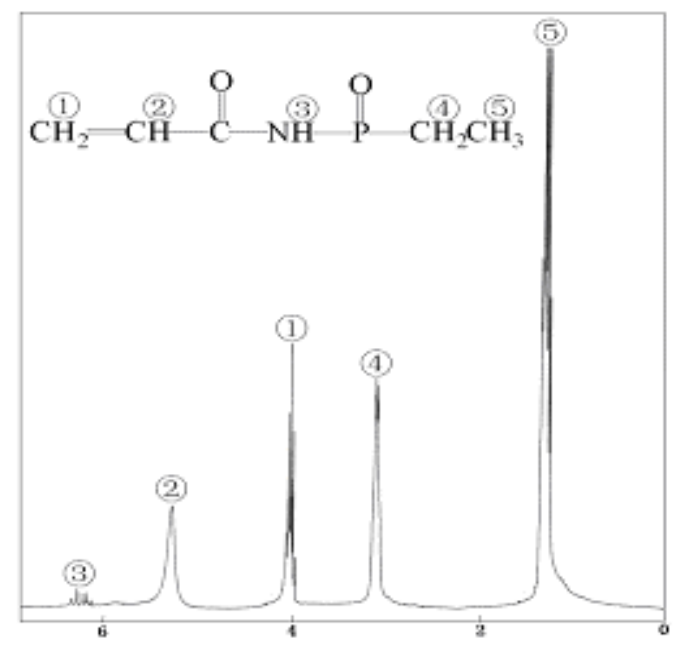

Figure 2. ${ }^{1} \mathrm{H}$ NMR Spectrum of the Title Compound

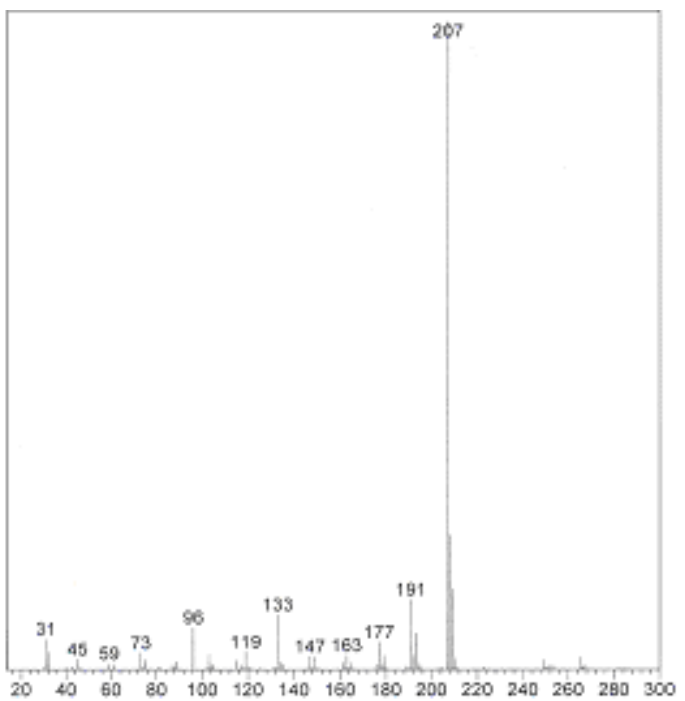

Figure 3. Mass Spectrum of the Title Compound

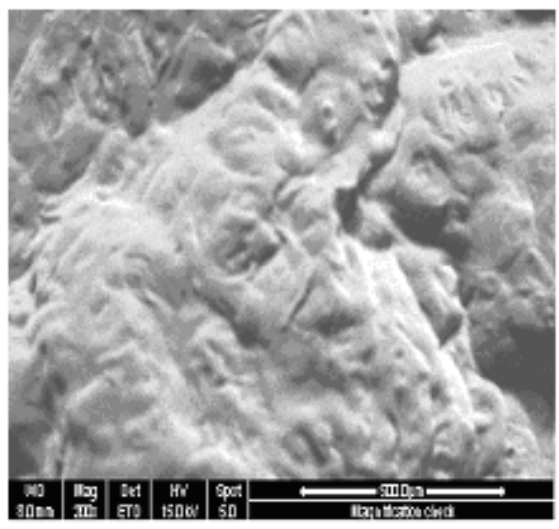

a. Surface photo of the fired copolymer residue

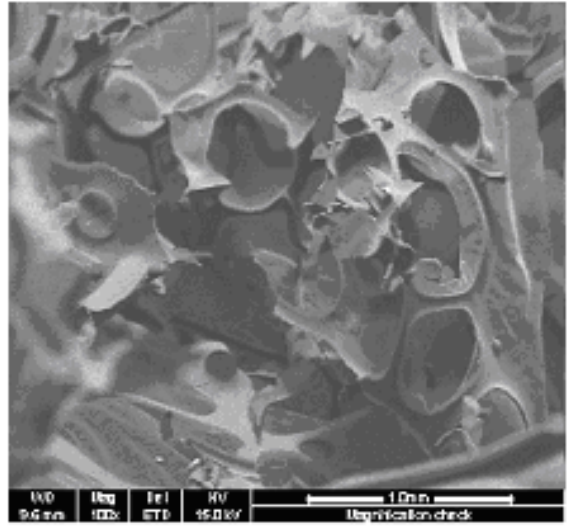

b. Cross-section photo of the fired copolymer residue

Figure 4. The Surface and Cross-section SEM Photos of the Fired Residue of Flame Retardant polyacrylonitrile copolymer 